\title{
Description of a new species of Dolichorchis (Digenea, Diplostomidae) in the cocoi heron, Ardea cocoi (Aves, Ardeidae), from Argentina
}

\author{
Lía I. Lunaschi* and Fabiana B. Drago \\ División Zoología Invertebrados, Museo de La Plata, Paseo del Bosque S/No 1900 La Plata, Buenos Aires, Argentina
}

\begin{abstract}
Dolichorchis lacombeensis sp. nov., a digenean parasite of the gut of the cocoi heron, Ardea cocoi (L.), is described as a new species from Buenos Aires Province. Argentina. This new species most closely resembles $D$. buteii and $D$. tregenna in the distribution of the vitelline follicles. which reach the intestinal bifurcation in the forebody. D. buteii can be distinguished from D. lacombeensis sp. nov. by the distribution of the vitelline follicles in the hindbody, which are concentrated in midline, by the presence of a sphincter in genital pore and by the size of holdfast organ and posterior testis, which are larger. (240-400 $\times$ 176-240 and 315-464 $\times 240-410 \mu \mathrm{m}$. respectively). D. tregenna differ from the new species by their larger measurements (pseudosuckers' length 90-100, pharynx 52-90 × 50-70 and eggs 89-104 × 48-68 $\mu \mathrm{m}$ ).
\end{abstract}

\section{Key words}

Dolichorchis lacombeensis sp. nov.. Digenea. Diplostomidae. Ardea cocoi, birds. Argentina

\section{Introduction}

During a parasitological survey of birds from the Lacombe Lagoon. Buenos Aires Province, Argentina, specimens of a species of Dolichorchis Dubois. 1961 were collected from the intestine of Ardea cocoi (L.) (Ardeidae). Members of this genus are diplostomoid digeneans that differ from other genera within the family by the presence of an anterior testis which is asymmetrical; a posterior testis which is symmetrical with elongate lobes; and a copulatory bursa enclosing the genital cone (Niewiadomska 2002). At present, the only known species of Dolichorchis in Neotropical region is D. bonariensis Ostrowski de Núñez, 1970 [as Diplostomum (Dolichorchis) bonariensis]. which was found in the gut of Phalacrocorax brasilianus (Gmelin) (Phalacrocoracidae) from Buenos Aires Province (Ostrowski de Núñez 1970). In the present report, a new species of Dolichorchis is described.

\section{Materials and methods}

One specimen of Ardea cocoi was captured in September 2003 at Lacombe Lagoon. Chascomús. Buenos Aires Prov- ince. The bird was dissected in the field and twelve specimens were fixed unflattened in hot formalin and preserved in formalin. Whole-mount specimens were stained in hydrochloric carmine and mounted in Canada balsam. In order to facilitate handling and observation. the specimens were mounted between two microscope coverslips. Drawings were made with the aid of a camera lucida. Unless otherwise stated, measurements are given in micrometers $(\mu \mathrm{m})$; the range is followed by the mean in parentheses. The material studied was deposited in Helminthological Collection of the Museo de La Plata. Argentina.

\section{Results}

Dolichorchis lacombeensis sp. nov. (Figs 1-3)

Description based on 12 whole-mounted specimens: Body fusiform, distinctly bipartite, 1.027-1.123 (1.096) $\mathrm{mm}$ length. Forebody spatulate, 619-720 × 317-379 $(688 \times 350)$; hindbody conical. $470-509 \times 235-250(488 \times 244)$. Ratio of forebody length to hindbody length 1:1.25-1.53 (1:1.41). Anterior part of forebody to the ventral sucker or the holdfast organ 
covered by fine spines. Oral sucker, 67-78 $\times 74-78(71 \times 77)$, subterminal nearly the same size as the ventral sucker, $62-77$ $\times 74-87(67 \times 80)$, located in middle third of forebody. Pseudosuckers, 58-69 × 44-58 $(64 \times 50)$, smaller than the oral sucker. Ratio of oral sucker length/pseudosuckers' length $1: 1.1-1.2(1: 1.1)$. Ratio of body length/pseudosuckers' length 1:16-18 (1:17). Ratio of forebody length/pseudosuckers' length 1:9.8 -11.6 (1:10.7). Distance between oral sucker and ventral sucker 269-361 (334). Suckers width ratio 1:0.90-1 (1:0.93). Holdfast organ oval, 116-141 × 103-116 (129 $\times$ 111 ), immediately posterior to the ventral sucker, 14-29 (22); proteolytic gland at junction of fore- and hindbody. Ratio of body length/holdfast organ length $1: 8-8.9$ (1:8.5). Ratio of forebody length/holdfast organ length $1: 4.9-5.7$ (1:5.3). Prepharynx absent; pharynx small, 46-51 × 23-31 (49 × 26); oesophagus short, 19-34 (24); intestinal caeca reach into posttesticular region. Ratio of oral sucker length to pharynx length $1: 1.4-1.5(1: 1.48)$. Ratio of pseudosuckers' length to pharynx length 1:1.2-1.4 (1:1.3). Testes tandem, relatively large, extended transversally occupying whole width of hindbody; anterior testis asymmetrical, 207-216(210) in width, curved; lobe $126-145 \times 53-115(134 \times 84)$; posterior testis longer than anterior, symmetrical, bilobed, with elongate lobes; $187-223$ (212) in width; lobes $138-195 \times 53-115(173 \times 73)$. Seminal
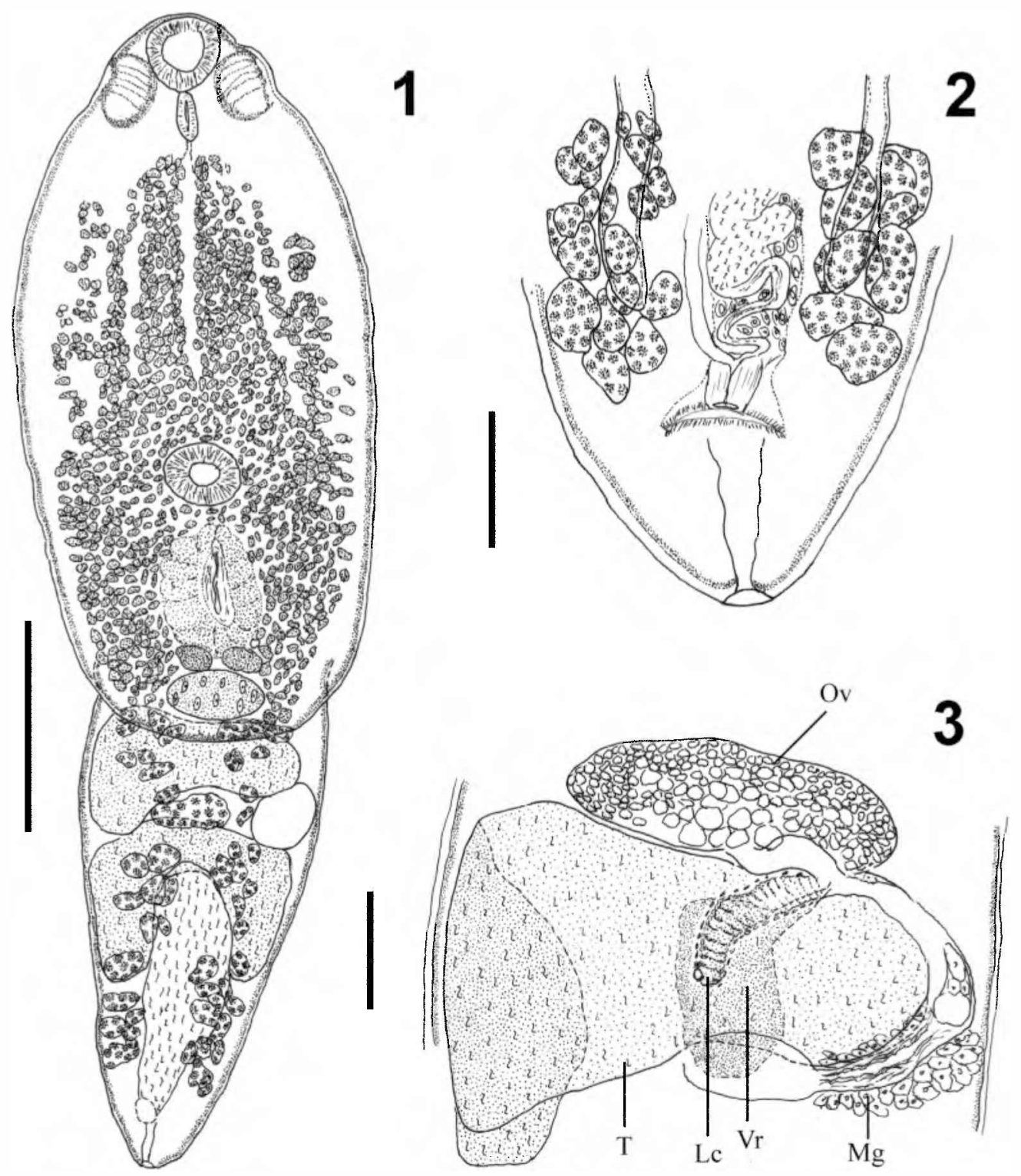

Figs 1-3. Dolichorchis lacombeensis sp. nov. from Ardea cocoi. 1. Holotype, entire worm ventral view. Scale bar $=200 \mu \mathrm{m}$. 2. Enlarged ventral view of terminal genitalia. Scale bar $=50 \mu \mathrm{m}$. 3. Enlarged dorsal view of proximal female genitalia. Scale bar $=50 \mu \mathrm{m}$. Abbreviations: $\mathrm{Lc}$ - Laurer's canal, $\mathrm{Mg}$ - Mehlis' gland, $\mathrm{Ov}$ - ovary, $\mathrm{T}$ - anterior testis, $\mathrm{Vr}$ - vitelline receptacle 
vesicle posterior to testes, long, sacciform, ventro-medial, 161-235 (196). Copulatory bursa not protrusible. with genital pore dorso-subterminal, enclosing small genital cone and hermaphroditic duct. Ovary median, ellipsoidal, pretesticular, at junction of fore- and hindbody, 44-61 × 107-135 $(51 \times$ 120). Oviduct short; Laurer's canal conspicuous, opening dorsally immediately posterior to level of the ovary in midline of body; Mehlis' gland situated latero-posteriorly to anterior testis; uterine seminal receptacle present. Vitellarium follicular, distributed in both parts of body, mainly in forebody and concentrated around holdfast organ. extending from close to level of intestinal bifurcation to posterior extremity of hindbody in two lateral fields; with vitelline reservoir ventral. intertesticular. Uterus not entering forebody, with 1-3 eggs in mature worms; 65-78 $\times 44-59$. Excretory pore terminal. Vesicle not seen.

Type host: Ardea cocoi (L.).

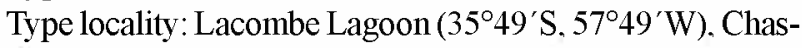
comús. Buenos Aires Province, Argentina.

Site: Small intestine.

Type material: Holotype and paratypes deposited in Helminthological Collection MLP. Argentina, number 5292.

\section{Discussion}

Dolichorchis lacombeensis sp. nov. corresponds with genus Dolichorchis Dubois, 1961 in such characters as bipartite body; present pseudosuckers; asymmetrical anterior testis; larger. symmetrical and bilobed posterior testis with elongate lobes; ovary near the junction between the fore- and hindbody; copulatory bursa with genital cone and hermaphroditic duct (Dubois 1961. Niewiadomska 2002).

The following species of the genus Dolichorchis were reported: D. tregenna Nazmi Gohar, 1932 in Buteo augur, Milvus migrans parasitus, $M$. migrans tenebrosus, $M$. aegyptius (Accipitridae) and Ardea cinerea (Ardeidae) from Africa; D. buteii Vidyarthi, 1937 in Buteo rufinus and Haliastur indus (Accipitridae) from India; D. ketupanense ketupanense Vidyarthi. 1937 in Bubo zevlonensis leschenault (Strigidae) from India; D. heronei Srivastava, 1954 from Ardeola gravi and A. ibis (Ardeidae) from India; D. marahoueense Baer, 1957 (type species) in Scotopelia peli (Strigidae) from Côte d'Ivoire. Africa; D. mashonense Beverley-Burton, 1963 in Ardea cinerea (Ardeidae) from Southern Rhodesia; D. ketupanense vietnamiae Odening. 1963 in Bubo zevlonensis orientalis (Strigidae) from Vietnam; D. auriculosum Dubois et Pearson. 1967 in Anhinga novaehollandiae (Anhingidae) from Australia; D. bonariensis Ostrowski de Núnez, 1970, in Phalacrocorax brasilianus (Phalacrocoracidae) from Buenos Aires Province, Argentina and D. galaxiae Smith et Hickman. 1983 in Ardea novaehollandiae from Tasmania (Dubois and Pearson 1963, Dubois 1970, Ostrowski de Núnez 1970. Smith and Hickman 1983).

Dolichorchis lacombeensis sp. nov. from Ardea cocoi differs from the majority of known species by the distribution of the vitelline follicles, which extend from the level of the intestinal bifurcation. D. bonariensis, D. marahoueense. D. mashonense, D. auriculosum. D. heronei, D. ketupanense ketupanense, D. ketupanense vietnamiae and D. galaxiae have the vitelline follicles limited to the ventral sucker. Furthermore. D. bonariensis differs from the new species by the presence of the oval forebody and by their larger measurements (body 1.147-2.109 × 0.629-1.258; oral sucker 78-143 × 117-143: ventral sucker $91-156 \times 143-182$; pharynx 65-91 × 39-78; oesophagus length 39-91, holdfast organ 286-455 × 208416: ovary 91-143 × 91-143).

Dolichorchis buteii and D. tregenna are similar to specimens obtained from Ardea cocoi in the distribution of the vitelline follicles in forebody. The new species can be distinguished from $D$. buteii by the distribution of the vitelline follicles in hindbody; in D. lacombeensis sp. nov. the vitelline follicles extend in two lateral fields. in D. buteii they are concentrated in midline; by the presence of a sphincter in genital pore in D. buteii and by the size of holdfast organ and posterior testis. which are larger in D. buteii. $(240-400 \times 176-240$ and 315-464 $\times 240-410$, respectively). Furthermore, it differs in the ratio of body length/pseudosuckers' length (28-52); ratio of oral sucker length/pseudosuckers' length (1.2-1.3); ratio of forebody length/pseudosuckers' length (12.9-25.9) and suckers' width ratio (1-1.5), which are larger in $D$. buteii and in the ratio of body length/holdfast organ length (7.4), ratio of oral sucker length to pharynx length (1.2-1.3), ratio of forebody length/holdfast organ length (1.8-3.7) and ratio of pseudosuckers' length to pharynx length (1) which are smaller in D. buteii.

Specimens obtained from $A$. cocoi can be distinguished from $D$. tregenna by the size of the pseudosuckers, pharynx and eggs. which are larger in D. tregenna $(90-100 ; 52-90 \times$ $50-70 ; 89-104 \times 48-68$, respectively). In addition, they differ in the ratio of forebody length to hindbody length (0.6-0.7). ratio of body length/pseudosuckers' length (11-16), ratio oral sucker length/pseudosuckers' length (0.6-1), ratio of body length/holdfast organ length (5.7-8) and ratio of oral sucker length to pharynx length (1.1) which are smaller in $D$. tregenna.

\section{References}

Dubois G. 1961. Le genre Diplostomum von Nordmann, 1832 (Trematoda: Strigeida). Bulletin de la Société Neuchâteloise des Sciences Naturelles, 84, 113-124.

Dubois G. 1970. Synopsis des Strigeidae et des Diplostomatidae (Trematoda). Mémoires de la Société Neuchâteloise des Sciences Naturelles, 10, 259-727.

Dubois G., Pearson J.C. 1963. Les Strigeida (Trematoda) d'Egypte (Collection William H. Wells). Annales de Parasitologie Humaine et Comparée, 38, 77-91.

Niewiadomska K. 2002. Family Diplostomidae Poirier, 1886. In: Keys to the Trematoda. Vol. 1 (Eds. D.I. Gibson, A. Jones and R.A. Bray). CABI Publishing and The Natural History Museum, Wallingford, 167-196.

Ostrowski de Núñez M. 1970. Estudios sobre la fauna parasitaria del biguá, Phalacrocorax b. brasilianus. Trematodes pertene- 
cientes a la familia Diplostomatidae. Revista del Museo Argentino de Ciencias Naturales "Bernardino Rivadavia", Zoología, 10, 199-214.

Smith S.J., Hickman J.L. 1983. Two strigeoid trematodes, Apatemon (Apatemon) gracilis (Rudolphi, 1819) and Diplostomum (Do- lichorchis) galaxiae n. sp., which encyst in the freshwater fish Galaxias auratus Johnston in lake Crescent, Tasmania. Papers and Proceedings of the Roval Society of Tasmania, 117, 21-39.

(Accepted November 10, 2005) 